\title{
Association of low numbers of CD206-positive cells with loss of ICC in the gastric body of patients with diabetic gastroparesis
}

C. E. BERNARD $,{ }^{\star}, \#$ S. J. GIBbONS $,{ }^{\star}, \#$ I. S. MANN,${ }^{\star}$ L. FrOSCHAUER, ${ }^{\star}$ H. P. PARKMAN,$\dagger$ S. HARBISON,+ T. L. ABELL,$\S$

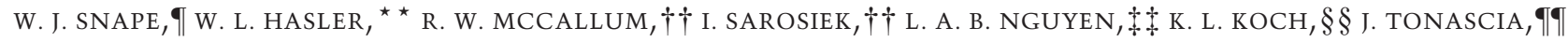
F. A. HAMILTON, ${ }^{\star}{ }^{\star}{ }^{\star}$ M. L. KENDRICK, ${ }^{\star}, \dagger \dagger \dagger$ K. R. SHEN $,{ }^{\star}, \dagger \dagger \dagger$ P. J. PASRICHA, $+\uparrow \dagger$ G. FARRUGIA ${ }^{\star}, \S \S \S \&$ ON BEHALF OF THE NIDDK GASTROPARESIS CLINICAL RESEARCH CONSORTIUM (GPCRC)

${ }^{\star}$ Enteric NeuroScience Program, Mayo Clinic, Rochester, MN, USA

$\dagger$ Department of Medicine, Division of Gastroenterology, Temple University Hospital, Philadelphia, PA, USA

$\ddagger$ Department of Surgery, Temple University Hospital, Philadelphia, PA, USA

$\S$ Division of Gastroenterology, University of Louisville, Louisville, KY, USA

qDivision of Gastroenterology, California Pacific Medical Center, San Francisco, CA, USA

* Division of Gastroenterology, University of Michigan Medical Center, Ann Arbor, MI, USA

$\dagger$ †Division of Gastroenterology, Internal Medicine, Texas Tech University Health Sciences Center, El Paso, TX, USA

†Division of Gastroenterology, Stanford University, Stanford, CA, USA

$\S \S$ Wake Forest University Health Sciences, Winston-Salem, NC, USA

qๆJohns Hopkins University, Baltimore, MD, USA

${ }^{\star \star \star}$ National Institute of Diabetes and Digestive and Kidney Diseases, Bethesda, MD, USA

$+\dagger$ Department of Surgery, Mayo Clinic, Rochester, MN, USA

HJohns Hopkins Bayview Medical Center, Baltimore, MD, USA

$\S \S \S$ Division of Gastroenterology, Mayo Clinic, Rochester, MN, USA

\section{Key Messages}

- This study was designed to identify and quantify macrophage populations and any associations with ICC in the normal human stomach and in gastroparesis.

- Quantification of immunoreactive cells using CD45, cKit, CD206 and iNOS was carried out on gastric body biopsies from 10 age-matched, female patients from each of the following groups; Controls, Diabetic Controls, Idiopathic Gastroparesis, and Diabetic Gastroparesis.

- Macrophages appear to play a cytoprotective role in the human stomach. There is a relationship between numbers of CD206 positive (alternatively activated, M2) macrophages and numbers of ICC in diabetic gastroparesis.

- The data suggest that therapeutic strategies may be explored that target alternatively activated macrophages.

\begin{abstract}
Background There is increasing evidence for specific cellular changes in the stomach of patients with
\end{abstract}

Address for Correspondence

Gianrico Farrugia, MD, Enteric NeuroScience Program, Mayo Clinic, 200 First Street SW, Rochester, MN 55905, USA.

Tel: 507-284-4695; fax: 507-284-0266;

e-mail: Farrugia.gianrico@mayo.edu

"Sharing equal contributions.

Received: 8 April 2014

Accepted for publication: 6 June 2014 diabetic (DG) and idiopathic (IG) gastroparesis. The most significant findings are loss of interstitial cells of Cajal (ICC), neuronal abnormalities, and an immune cellular infiltrate. Studies done in diabetic mice have shown a cytoprotective effect of CD206+ M2 macrophages. To quantify overall immune cellular infiltrate, identify macrophage populations, and quantify CD206+ and iNOS+ cells. To investigate associations between cellular phenotypes and ICC. Methods Full thickness gastric body biopsies were obtained from non-diabetic controls (C), diabetic controls (DC), DG, 
and IG patients. Sections were labeled for CD45, CD206, Kit, iNOS, and putative human macrophage markers (HAM56, CD68, and EMR1). Immunoreactive cells were quantified from the circular muscle layer. Key Results Significantly fewer ICC were detected in $D G$ and IG tissues, but there were no differences in the numbers of cells immunoreactive for other markers between patient groups. There was a significant correlation between the number of CD206+ cells and ICC in $D G$ and DC patients, but not in $C$ and $I G$ and $a$ significant correlation between iNOS+ cells and ICC in the DC group, but not the other groups. CD68 and HAM56 reliably labeled the same cell populations, but EMR1 labeled other cell types. Conclusions \& Inferences Depletion of ICC and correlation with changes in CD206+ cell numbers in DC and DG patients suggests that in humans, like mice, CD206+ macrophages may play a cytoprotective role in diabetes. These findings may lead to novel therapeutic options, targeting alternatively activated macrophages.

Keywords gastroparesis, interstitial cells of Cajal, macrophages.

Therapies for gastroparesis have not changed significantly for many years and gastroparesis remains a significant challenge for both patients and providers. ${ }^{1-4}$ Gastroparesis continues to be a significant and costly health issue. ${ }^{2,5,6}$ Animal models have recently begun to provide new information on the pathophysiology of gastroparesis with identification of several new targets, including enteric nerves, ${ }^{7,8}$ interstitial cells of Cajal $(\text { ICC })^{8-11}$, and most recently macrophages. ${ }^{11,12}$ There are now several animal model and human tissue studies that show that ICC are reduced in gastroparesis. A recently published study from the NIH sponsored Gastroparesis Clinical Research Consortium showed that loss of ICC is the most common defect seen and occurs in both human diabetic and idiopathic gastroparesis (IG). ${ }^{13}$ Neuronal changes were also seen, especially at the electron microscopy level. ${ }^{14}$ The studies also showed that CD45 positivity, used as generic marker of immune cells, was increased in a subset of patients in the myenteric plexus of gastroparetic patients. ${ }^{13}$ No correlation between CD45-positive cell infiltrate and ICC loss was found in either diabetic or IG. ${ }^{15}$

Animal studies have suggested an important role of macrophages in the pathophysiology of gastroparesis. ${ }^{11,12}$ Studies in diabetic non-obese diabetic mice have suggested that a defined series of events leads to development of delayed gastric emptying. These events are closely linked to changes in the phenotype of macrophage populations in the muscularis propria as indicated by the expression of well-defined markers for mouse macrophages. All macrophages in the mouse stomach are immuno-labeled with F4/80, a monoclonal antibody against a membrane glycoprotein, this includes resident, classically activated, and alternatively activated macrophages. ${ }^{16,17}$ Classically activated macrophages, also known as M1 macrophages, express inducible nitric oxide synthase (iNOS, NOS2) among other markers and nitric oxide $(\mathrm{NO})$ is an important cytotoxic product of these cells. ${ }^{18,19}$ Alternatively activated or M2 macrophages express the mannose receptors (CD206) and heme oxygenase-1 (HO1) and mediate cell repair and have anti-inflammatory roles. ${ }^{18,19}$ In mice, under normal conditions, development of diabetes and the concomitant increase in oxidative stress result in activation of M2 macrophages that are protective against development of delayed gastric emptying. In susceptible animals, prolonged diabetes leads to loss of the M2 macrophages and increased numbers of HO1-negative, M1 macrophages that express iNOS, damage to ICC networks, and development of delayed gastric emptying. ${ }^{11,12}$

It is not known if the findings in the mouse models are also applicable to human gastroparesis. The classification of human macrophages is not as well defined as for mouse cells and human macrophages do not appear to express iNOS ${ }^{20}$ due to an epigenetic silencing mechanism that is present in human, but not mouse macrophages. ${ }^{21}$ However, alternatively activated, M2like human macrophages do express the mannose receptor (CD206). ${ }^{19}$ For general markers, several have been proposed to label all macrophage types in a variety of tissues. These include CD68, a cell surface marker identified on the majority of macrophages ${ }^{22}$, but also found on other cell types, ${ }^{23}$ HAM56, which is expressed on a broad range of cells belonging to the macrophage lineage $e^{24,25,26}$ albeit with some evidence for labeling of endothelial cells ${ }^{25}$ and EMR1, the human homolog of F4/80. ${ }^{27}$ Identification of the involvement of macrophages may identify new therapeutic targets, but there has been limited characterization of macrophages in the muscularis propria of human gastrointestinal tissue. ${ }^{17,28-30}$ In this study, we assessed the reliability of HAM56, CD68, and EMR1 as selective markers of macrophages in human gastric muscularis propria. We also quantified CD45positive cells as a measure of general immune cell infiltrate in tissues from patients with diabetic and IG, quantified CD206-positive cells as a measure of antiinflammatory macrophages, quantified iNOS-positive cells as a measure of an increased inflammatory environment in the tissues, and studied the relationship between CD45, CD206, and iNOS-positive cell numbers and ICC numbers. 


\section{METHODS}

Full thickness biopsies of the gastric body were studied from 10 age-matched female patients in four different groups. Control tissues were obtained during bariatric surgery from non-diabetic (C) (median age 46; age range 26-59) and diabetic control (DC; median age 49; age range 33-59) patients with no motility disorders. Tissue from patients with diabetic gastroparesis (DG), all with Type I diabetes (median age 43; age range 28-60) and IG (median age 44; age range 26-64) were obtained at the time of gastric electrical stimulator implantation, as previously described. ${ }^{13} \mathrm{Immu}$ noreactive cells were quantified from eight nonadjacent, $12 \mu \mathrm{m}$ frozen sections, from each patient. Images were collected from 48 fields in the circular muscle (CM) layer of doubly labeled sections, using a $40 \times / 1.0$ NA, UPlanApo, oil immersion Olympus objective and XM10 digital camera. Cells were counted from images that were de-identified by renaming with a random number generated using a web-based random number generator (www.random.org). Immunoreactive cells were defined as a positively labeled structure with a 4',6-diamidino-2-phenylindole (DAPI)-positive nucleus within the structure.

Immunohistochemistry was done as follows. In one set, we doubly labeled sections using a mouse monoclonal antibody against Kit as a marker for ICC (US Biological, Salem, MA, USA) and a goat polyclonal antibody to CD206 (Santa Cruz, Santa Cruz, CA , USA) as a marker for M2 (alternatively activated macrophages). Sections of tissue were warmed to room temperature in a desiccator and rinsed twice in 1X PBS followed by a blocking step for non-specific antibody binding by incubating the tissue in $1 \mathrm{X}$ PBS, $1 \%$ bovine serum albumin (BSA), and $0.3 \%$ Triton $\mathrm{X}$ 100 for an hour at room temperature. The antibodies (Table S1) were diluted in 1X PBS, $1 \%$ BSA, and $0.3 \%$ Triton X-100, and incubated overnight at $4{ }^{\circ} \mathrm{C}$. Next, slides were rinsed in $1 \mathrm{X}$ PBS five times, followed by a $1 \mathrm{~h}$ incubations with secondary antibodies (Table S1) diluted in $1 \mathrm{X}$ PBS, $1 \%$ BSA, $0.3 \%$ Triton X-100 at room temperature. The slides were rinsed five times in $1 \mathrm{X}$ PBS and mounted in SlowFade Gold with DAPI (Invitrogen, Carlsbad, CA, USA). In another set, we doubly labeled sections using a mouse monoclonal to CD45 (AbD Serotec, Raleigh, NC, USA) as a general marker for immune cell infiltrate and a rabbit polyclonal to iNOS (Thermo Scientific, Pittsburgh, PA, USA) as an indicator of increased inflammatory cells in the tissues. Slides were rinsed twice in 1X PBS, followed by an addition of Image-iT FX Signal Enhancer for $30 \mathrm{~min}$. The slides were rinsed twice in 1X PBS, followed by a $1 \mathrm{~h}$ block with $1 \mathrm{X}$ PBS, $1 \%$ BSA, $0.3 \%$ Triton X-100. Primary antibodies were added in $1 \mathrm{X}$ PBS, $1 \%$ BSA, $0.3 \%$ Triton, and incubated overnight at $4{ }^{\circ} \mathrm{C}$. The protocol was finished as described above.

There is a lack of a well-established, well-validated general marker for human macrophages in gastric muscularis propria. Therefore, we investigated several different antibodies which have been published as markers for human macrophages. These included CD 68 (mouse monoclonal, DAKO, Carpinteria, CA, USA), ${ }^{31}$ EMR1 (rabbit polyclonal, MBL International, Woburn, MA, USA) ${ }^{27}$, and HAM56 (mouse monoclonal, Thermo Scientific). ${ }^{32}$ We also doubly labeled for CD68 with HAM56, CD68 with EMR1, and HAM56 with EMR1. The protocol for immunohistochemistry on the doubly labeled slides using Ham 56 and EMR1 was followed as described above. In the slides doubly labeled for CD68 (mouse monoclonal, Isotype IgG3, kappa) and HAM56 (mouse monoclonal, Isoptype IgM) the protocol is as follows. Sections of tissue were warmed to room temperature in a desiccator. While tissue is warming, place $1 \mathrm{mM}$ EDTA, $\mathrm{pH} 8.0$ in a plastic coplin jar and heat in a $60^{\circ}$ water bath. Rinse slides for $2 \mathrm{~min}$, twice in 1X PBS. Place slides in heated EDTA and heat for $60 \mathrm{~min}$ in uncovered jar in water bath. Remove Coplin jar from water bath, let slides cool in EDTA for 5 min while covered. Rinse slides under faucet with cool running distilled water for $5 \mathrm{~min}$. Rinse slides twice in $1 \mathrm{X}$ PBS for $5 \mathrm{~min}$, followed by a $1 \mathrm{~h}$ block in 1X PBS, 1\% BSA, and $0.3 \%$ Triton X-100 at room temperature. HAM56 was diluted in blocking buffer and added to the slides and incubated overnight at $4{ }^{\circ} \mathrm{C}$. The next day, slides were rinsed five times in $1 \mathrm{X}$ PBS for $5 \mathrm{~min}$ and the secondary antibody (IgM) was added and incubated for $1 \mathrm{~h}$. The slides were then rinsed five times in 1X PBS for $5 \mathrm{~min}$ followed by a $1 \mathrm{~h}$ block in $1 \mathrm{X}$ PBS, $1 \%$ BSA, and $0.3 \%$ Triton X-100 at room temperature. CD68 was diluted in blocking buffer and added to the slides and incubated overnight at $4{ }^{\circ} \mathrm{C}$. The next day slides were rinsed five times in $1 \mathrm{X}$ PBS for $5 \mathrm{~min}$ and the secondary antibody (IgG) was added and incubated for $1 \mathrm{~h}$. Slides were rinsed five times in 1X PBS and mounted in SlowFade Gold with DAPI (Invitrogen). For all antibodies used, we carried out serial dilutions to determine the optimal antibody titers and positive and negative controls.

Statistical differences were determined using oneway ANOVA and correlations were determined by fitting using linear regression in Prism (Graphpad, La Jolla, CA, USA). 


\section{RESULTS}

There were significantly fewer ICC detected in the CM layer of gastroparetic samples when compared to control samples $(p=0.0171$ by one-way ANOVA, with Newman-Keuls posttest, Fig. 1; DG: $1.67 \pm 0.6$, IG: $2.1 \pm 0.5, \quad$ C: $4.95 \pm 1.2, \quad$ DC: $3.8 \pm 0.72 \mathrm{ICC} /$ field, $n=10, p<0.05$, ANOVA). This finding is consistent with our previous findings. ${ }^{13}$ An immune infiltrate was present within the CM layer of all four groups (Fig. 2). On quantification, the number of CD45positive cells was not different between the four groups $(p<0.05$, one-way ANova, Fig. 2 ; DG: $8.61 \pm 0.8$, IG: $9.48 \pm 1.1$, DC: $9.85 \pm 1.99$, C: $8.90 \pm 0.7$ cells per field). There were no significant correlations for any of the four groups (Fig. 3) between numbers of CD45positive cells and ICC.

To investigate which pan-macrophage marker is best to use in the human stomach wall, we tested and compared labeling of CD68, EMR1, and HAM56. We observed that CD68 immunoreactivity overlapped with HAM56 immunoreactivity in the vast majority of cells (Fig. 4). However, there were some HAM56positive cells that were CD68 negative (arrows in Fig. 4C) and CD68-positive cells that were HAM56 negative (arrowheads in Fig. 4C). CD68 double labeled with EMR1 showed little overlap between cells. EMR1-positive cells were more abundant than CD68positive cells. There were either CD68-positive cells or EMR1-positive cells but not both suggesting each labeled a separate population. This observation was supported by doubly labeling for HAM56 and EMR1. This observation showed little overlap between the two populations with more HAM56-positive cells that were EMR1 negative and some EMR1 positive but

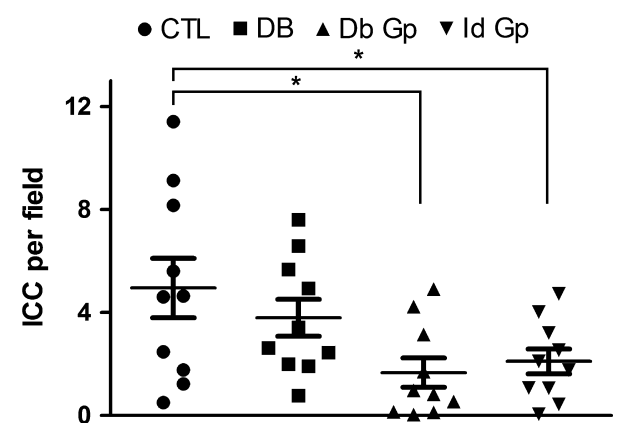

Figure 1 Significantly fewer ICC were detected in the circular muscle layer of Idiopathic Gastroparesis (IG, $2.1 \pm 0.5$ cells/field) and Diabetic Gastroparesis (DG, $1.67 \pm 0.6$ cells/field) compared to Controls (C, $4.95 \pm 1.2$ cells/field) and Diabetic Controls (DC, $3.8 \pm 0.72$ cells/ field). Data show average values for counts from 39 fields from each patient as points, population means \pm SEM shown as whiskers, $n=10$ patients for each group, * indicates $p<0.05$, one-way ANOvA with Newman-Keuls posttest.
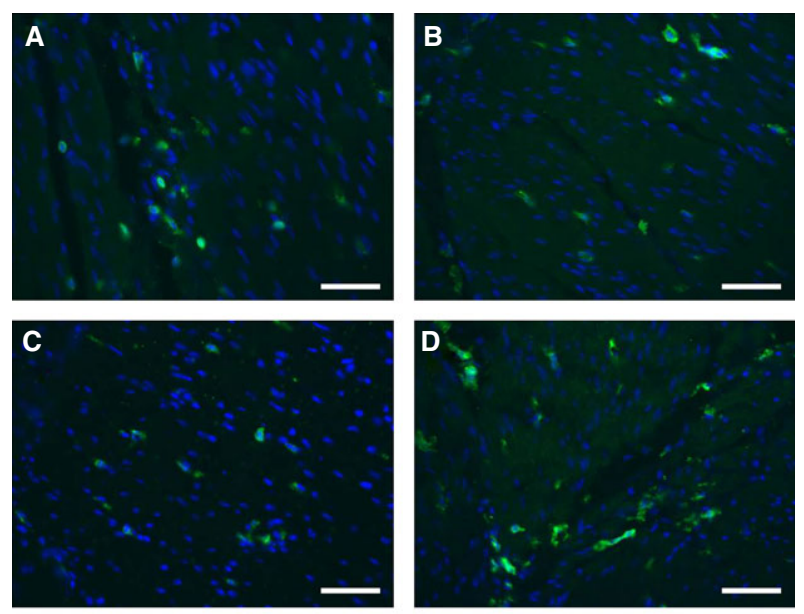

E

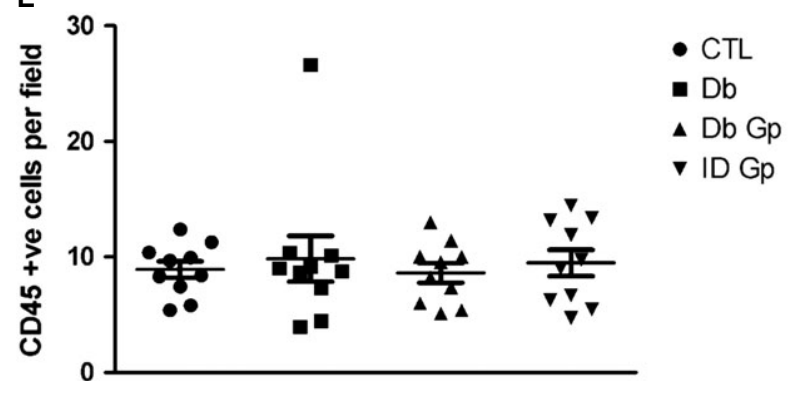

Figure 2 Representative images for CD45 immunoreactivity in the gastric circular muscle layer from (A) Control (B) Diabetic Control (C) Idiopathic Gastroparesis (D) Diabetic Gastroparesis; scale bar $=100 \mu \mathrm{M}$. (E) Number of CD45-positive cells was not different between the four groups. Data show average values for counts from 39 fields from each patient as points, population means \pm SEM shown whiskers, $n=10$ patients for each group, $p>0.05$, one-way ANOvA.

HAM56-negative cells. These data suggest that CD68 and HAM56 are better markers for the total macrophage population in the human stomach than EMR1.

In diabetic non-obese diabetic mice, the presence of CD206-positive macrophages is associated with protection against the development of delayed gastric emptying. In this mouse model, CD206 macrophages are present in large numbers in mice with diabetes with normal gastric emptying and decreased in mice with diabetes and delayed gastric emptying. CD206 (a marker for M2, alternatively activated macrophages)positive cells were quantified in the CM layer of all four groups (Fig. 5). CD206-positive cell numbers were not significantly different in any of the four groups $(p>0.05$, one-way ANOva, Fig. 5$)$ with a wide variation in the number of CD206-positive cells per field. However, there was a significant correlation between number of CD206-positive cells and numbers of ICC in both DC samples $(p=0.0285)$ and diabetic gastroparetic samples $(p=0.001$, Fig. 6$)$. There was no 
Figure 3 No correlation between number of CD45-positive cells and ICC (A) Control: $r^{2}=0.111$, Slope $=0.536 \pm 0.538$; (B) Diabetic Control: $r^{2}=0.335$ Slope $=0.209 \pm 0.104 ;(C)$ Idiopathic Gastroparesis: $r^{2}=0.3215$,

Slope $=-0.241 \pm 0.124 ;(\mathrm{D})$ Diabetic Gastroparesis: $r^{2}=0.008$,

Slope $=0.062 \pm 0.238$. Each point represents the data from a single patient and are means \pm SEM for counts from 39 fields. Data were fit by linear regression using Graphpad Prism. Dark line shows the fit, Gray dotted lines show the $95 \%$ confidence limits for the fit.
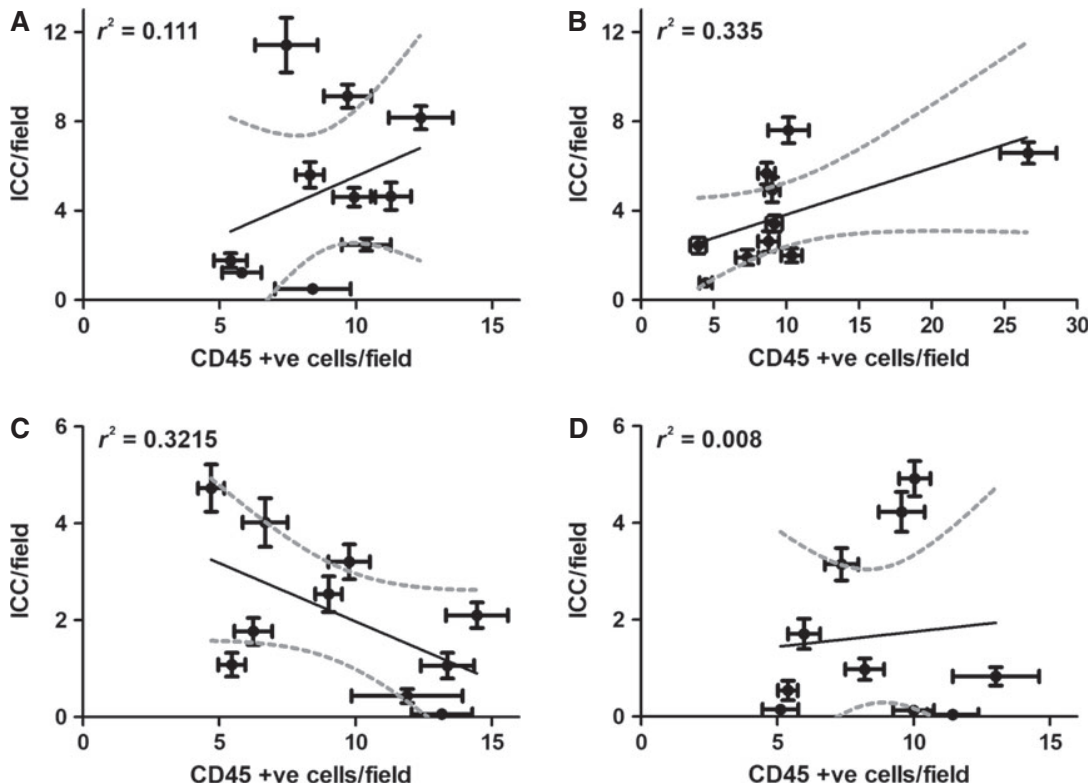

significant correlation between CD206-positive cells compared to numbers of ICC in control and idiopathic gastroparetic samples ( $p<0.05$, Fig. 6).

Development of delayed gastric emptying is associated with the presence of M1 classically activated macrophages in the gastric wall in diabetic mice. ${ }^{12}$ These cells express high levels of iNOS, so we investigated whether iNOS immunoreactivity was different in the tissues from the four groups. The numbers of iNOS-positive cells were not different between the four groups ( $p=<0.05$, Fig. 7). However, there was a significant correlation between the numbers of iNOS-positive cells and the numbers of ICC in the DC group $(p=0.0012)$, but not in any of the other groups (Fig. 8). To determine the percentage of iNOSpositive cells that were positive for an immune cell marker, we doubly labeled the tissues for iNOS and CD45. Only a small portion of iNOS-positive cells were CD45-positive in all four groups (DG: $22 \pm 2 \%$, IG: $19 \pm 2 \%$, DC: $32 \pm 5 \%$, C: $30 \pm 5 \%$ ), an observation that is consistent with iNOS being a poor marker for classically activated macrophages in the human stomach.

\section{DISCUSSION}

Animal models have provided highly valuable information on the cellular changes associated with the development of DG. A major finding emerging from these models is the unexpected role macrophages play in the pathophysiology of DG and the relationship between macrophage type and disruption of the number or function of key cell types involved in the regulation of gastric motility such as enteric nerves and ICC. ${ }^{11,12}$ The current study was designed to determine if similar changes also occur in human gastroparesis and if there were differences between diabetic and IG. The study builds on a previously reported finding by the NIH funded gastroparesis clinical research consortium of a CD45positive infiltrate in a subset of patients with gastroparesis. ${ }^{13}$

Several conclusions may be made from the data. We found, using a different cohort of patients from the previously reported study from the gastroparesis clinical research consortium, ${ }^{13}$ that there was a decrease in ICC numbers in the $\mathrm{CM}$ of gastroparetic samples
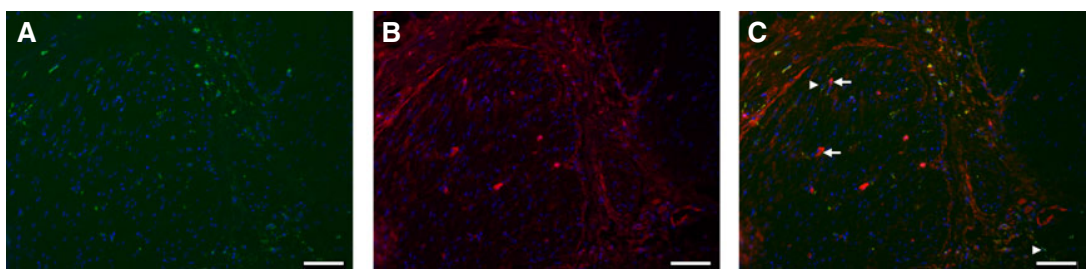

Figure 4 Representative images of macrophages markers (A) CD68 (B) HAM56 (C) Merged image (CD68 green) and (HAM56 red) in the circular muscle layer from the gastric body. White arrowhead shows CD68-positive, HAM56-negative cells. White arrow shows CD68-negative, HAM56positive cells; scale bar $=100 \mu \mathrm{M}$. 

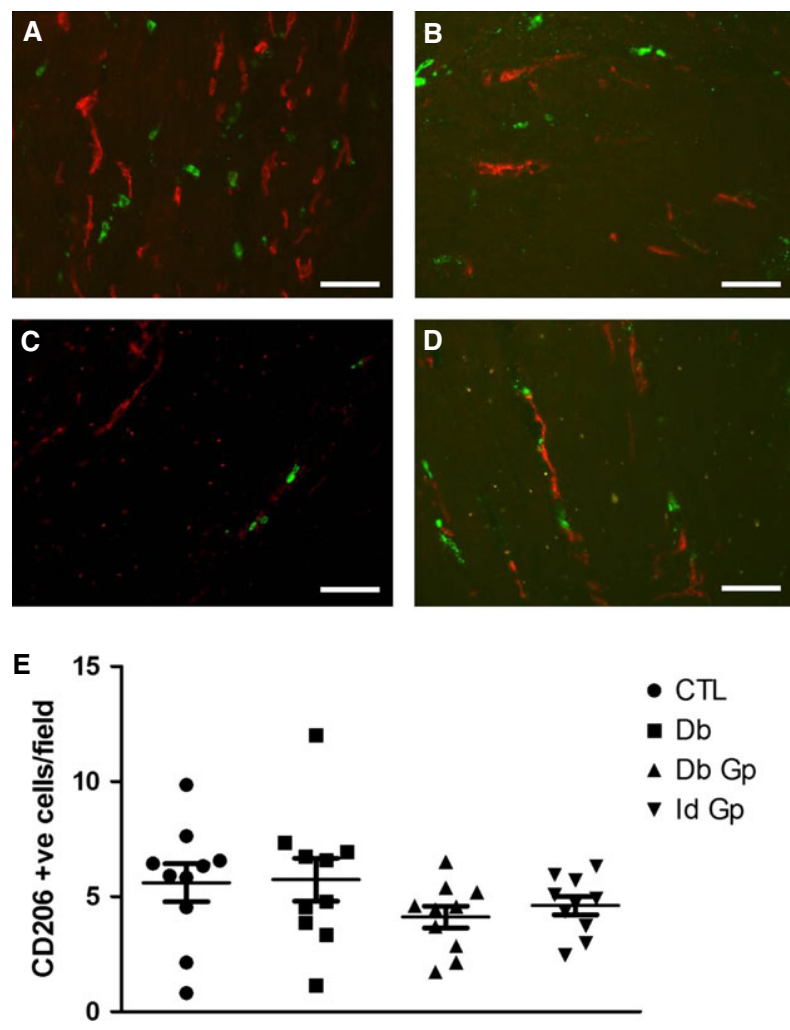

Figure 5 Representative images for CD206 immunoreactivity in the gastric circular muscle layer from (A) Control (B) Diabetic Control (C) Idiopathic Gastroparesis (D) Diabetic Gastroparesis; scale bar $=100 \mu \mathrm{M}$. (E) Number of CD206-positive cells was not different between the four groups. Data show average values for counts from 39 fields from each patient as points, population means \pm SEM shown whiskers, $n=10$ patients for each group, $p>0.05$, one-way ANOVA.

compared to controls. This is in agreement with a growing number of human studies that show similar levels of loss of ICC in both diabetic and IG ${ }^{14,33-40}$ and a correlation between the degree of ICC loss and gastric emptying in DG. ${ }^{15}$

The main finding of this study is that there was a significant correlation between number of ICC and CD206 numbers in diabetic gastric tissue and diabetic gastroparetic tissue. This is consistent with the finding in mice that CD206-positive M2 macrophages are protective $^{12}$ and suggests that a similar mechanism is operative in DG. However, there are also differences. In the mouse, M1 and M2 macrophage numbers in the stomach wall were relatively discordant. That is, in diabetic mice with normal gastric emptying over $90 \%$ of macrophages were M2 macrophages, whereas in diabetic mice with delayed gastric emptying less than $5 \%$ of macrophages had the M2 phenotype. In humans, it appears that both types of macrophages are present and it is the relative percentage that determines cytoprotection vs injury.
However, a significant caveat is that much less is known about the subtypes of human macrophages, what receptors are expressed and if and how they vary from organ to organ. It still remains unclear whether human CD206-positive macrophages have a similar cytoprotective function as mouse M2 macrophages. In mice, a reliable and relatively specific pan-macrophage marker is $\mathrm{F} 4 / 80 .{ }^{16} \mathrm{~F} 4 / 80$ is a membrane protein shown to be a marker for mature mouse macrophages and blood monocytes. ${ }^{16,41}$ The exact role of F4/80 is not known, but the sequence has adhesion and signaling domains suggesting a potential role in these pathways. ${ }^{16,41}$ The human homolog of F4/80 is EMR1, ${ }^{42}$ located on chromosome 19 with $68 \%$ sequence homology to F4/80. EMR1 has therefore been used as a marker for human macrophages. ${ }^{27,43}$ We found that EMR1 is a poor marker for human gastric macrophages as there was practically no overlap between EMR1-positive cells and CD68 or HAM56, both published as human macrophage markers. ${ }^{29,32,44,45}$ Our finding is in line with a study examining the surface expression of EMR1 using quantitative real-time PCR and flow cytometry. This study also found that EMR1 was not expressed on monocytes or macrophages, but labeled eosinophils in humans. ${ }^{27}$ EMR1 should therefore not be used as a human macrophage marker. Hamann et al. suggest that EMR1 is a specific human eosinophil marker, but the large number of cells labeled with EMR1 in the human stomach in our study suggest it is not specific to eosinophils. In contrast to EMR1, there was general agreement between labeling using CD68 or HAM56 antibodies. The number of cells labeled and the fact that there were some HAM56positive cells that were CD68 negative as well as CD68positive cells that were HAM56 negative suggests that the antibodies are labeling other cell populations together with macrophages and/or that they label different subsets of macrophages. Our data, taken with the literature $23,27,46$ suggest that both can be used as macrophage markers, but that care must be taken in interpreting results obtained using these antibodies as other studies carried out using CD68 as a macrophage marker have found that CD68 labels other hematopoietic and non-hematopoietic cells. ${ }^{23,47}$

iNOS is expressed in M1 macrophages in mice ${ }^{48}$ and some studies have reported transient expression of iNOS in human cells of the macrophage/monocyte lineage. ${ }^{49}$ We were therefore interested to see if iNOS expression was present in the human stomach wall, if it could be used as a marker for human gastric macrophages and if expression varied between gastroparesis and normal gastric emptying. We found no difference in the expression of iNOS across all four groups. Less than a third of iNOS-positive cells were 
Figure 6 Correlation between number of CD206-positive cells and ICC. There was no correlation between CD206-positive cells and ICC in (A) Controls and (C) Idiopathic Gastroparesis. There was a significant correlation between CD206-positive cells and ICC in (B) Diabetic Controls

$(p=0.0285)$ and (D) Diabetic Gastroparesis $(p=0.001)$. Each point represents the data from a single patient and are means \pm SEM for counts from 39 fields. Data were fit by linear regression using Graphpad Prism. Dark line shows the fit, Gray dotted lines show the $95 \%$ confidence limits for the fit.
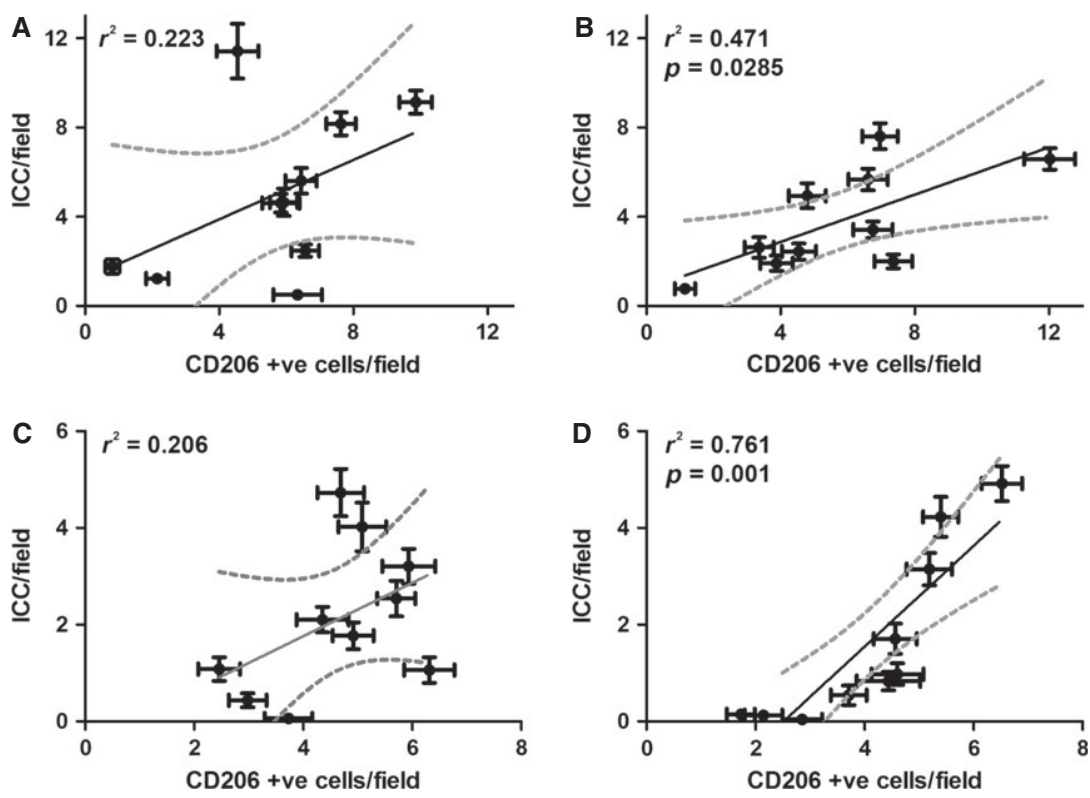

CD45 positive suggesting that the majority of iNOSpositive cells in the human gastric muscle wall are not immune cells and therefore not macrophages. iNOS therefore cannot be used as a specific marker for either immune cells or specifically M1 macrophages in the stomach. Some of the iNOS-positive cells had the visual appearance of fibroblast like type cells. We did double labeled iNOS with PDGFR $\alpha$ and Kit (data not shown). There was no overlap between iNOS and PDGFR $\alpha$ nor iNOS and Kit suggesting that these cells were not fibroblast like cells nor ICC. This finding also suggests that the iNOS antibody is not a suitable marker for M1, classically activated macrophages. There currently are no other markers that have been shown to label M1 macrophages and also label human macrophages. Development of such markers is necessary to allow the field to progress and also address relationships between M1 macrophages disease subtypes. In our initial report, ${ }^{13}$ we found an immune infiltrate in the human stomach with a qualitative increase in number of CD68-positive cells in the myenteric region in a subset of patients with gastroparesis. Antibodies used for B cells (CD79), T cells (CD3), and T-helper cells (CD4) showed no differences in immunolabeling between controls and gastroparetic samples. ${ }^{13}$ This suggested that the immune cell infiltrate was not due to B or T cells. The current study using a more rigorous quantitative methodology showed that there was indeed a CD45-positive immune cell infiltrate in the CM, but it was not different among the four groups. The association between number of CD206-positive cells and ICC suggest that together with quantifying numbers and
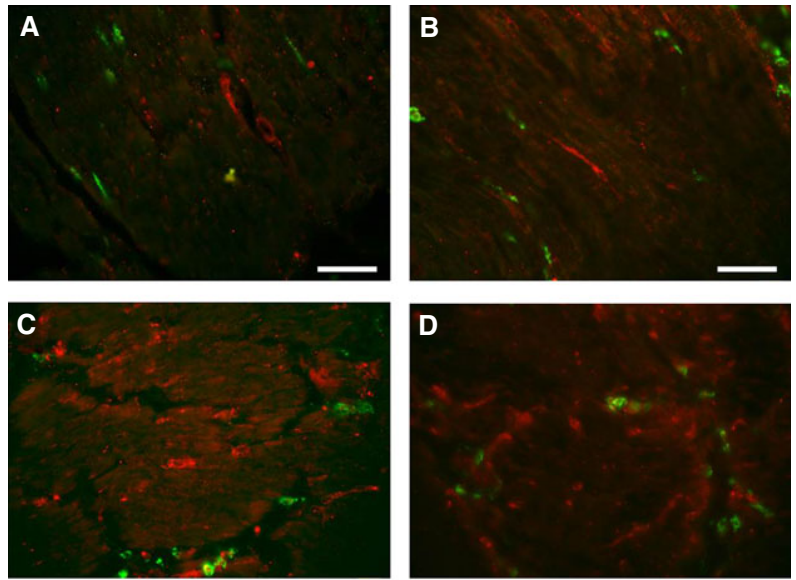

E

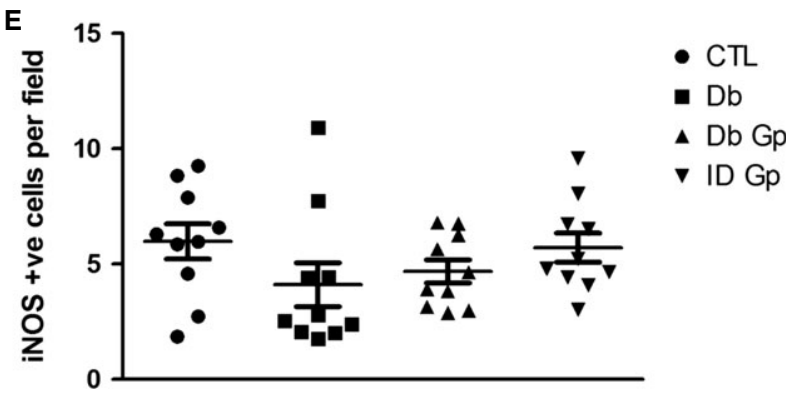

Figure 7 Representative images for iNOS immunoreactivity in the gastric circular muscle layer from (A) Control (B) Diabetic Control (C) Idiopathic Gastroparesis(D)Diabetic Gastroparesis. (E)Number of iNOS-positive cells is not different between the four groups. Data show average values for counts from 39 fields from each patient as points, population means \pm SEM shown whiskers, $n=10$ patients for each group $(p>0.05$, one-way ANOvA).

determining the type of immune cells, the relative numbers of different cell types (e.g., M1 vs M2 macrophages) and the spatial relationship between 

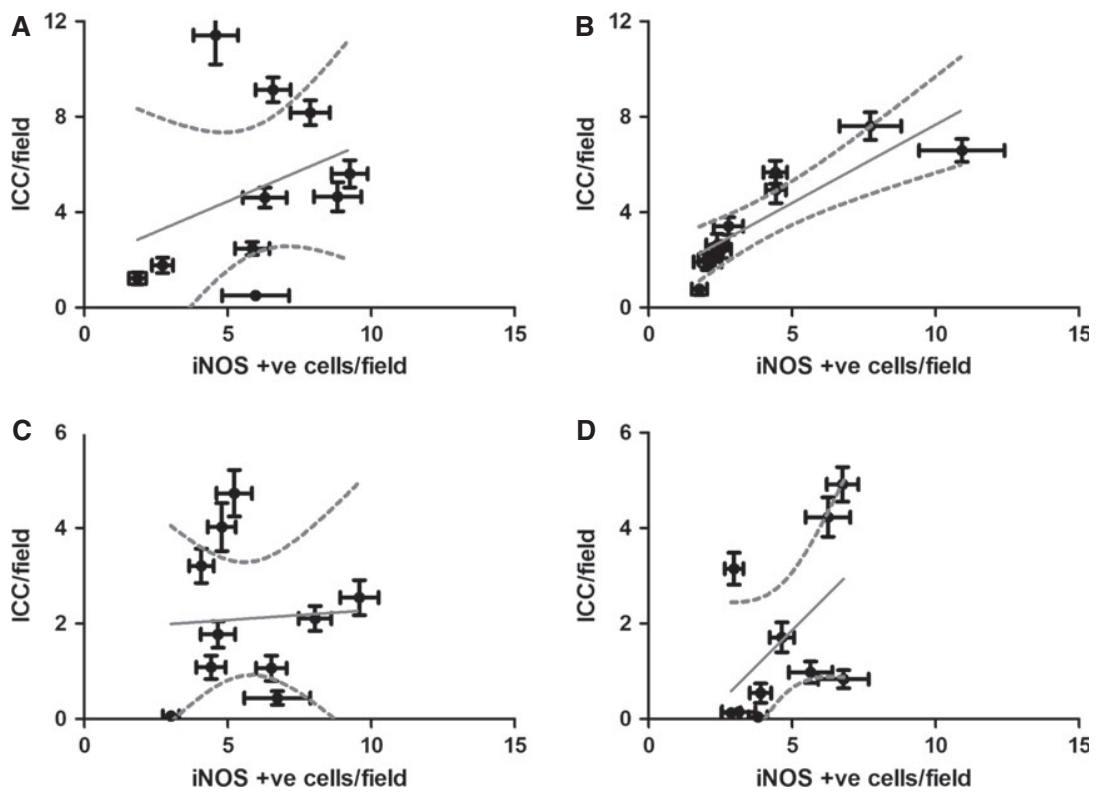

Figure 8 Correlation between number iNOS-positive cells and ICC. There was no significant correlation between iNOSpositive cells and ICC in (A) Controls (C) Idiopathic Gastroparesis and (D) Diabetic Gastroparesis. There was a correlation between number iNOS-positive cells and ICC in (B) Diabetic Controls $(p=0.0012)$. Each point represents the data from a single patient and are means \pm SEM for counts from 39 fields. Data were fit by linear regression using Graphpad Prism. Dark line shows the fit, Gray dotted lines show the $95 \%$ confidence limits for the fit.

cells may also be of importance. This will need to be addressed in future studies.

At an immunohistochemical level, few differences are apparent between diabetic and $\mathrm{IG}^{13,14}$ with loss of ICC and neuronal abnormalities described in both groups and differences limited largely to the transmission electron microscopy level. The finding in this study of a relationship between number of CD206-positive cells and number of ICC in diabetic but not IG suggests that while the end cellular damage at a light microscopy level is similar, the mechanisms that lead to such damage may be very different. This is perhaps not surprising given the high levels of reactive oxygen species and oxidative stress associated with diabetes. ${ }^{50}$

In conclusion, the main finding of this study is that there is a relationship between numbers of human CD206-positive macrophages and numbers of ICC suggesting that, in agreement with previous animal studies, CD206-positive macrophages may play a cytoprotective role in the human stomach. This finding opens up the opportunity to develop therapeutic strategies that target alternatively activated CD206positive macrophages.

\section{ACKNOWLEDGMENTS}

We thank Linda Lee, ML Van Natta, and Aynur Unalp-Arida for their valuable input to the design and execution of the study. We thank Dr. Kyoung Moo Choi for assistance with image capture. We also thank Peter Strege and Kristy Zodrow for excellent technical and secretarial assistance.

\section{FUNDING}

This work was supported by NIH DK68055, DK57061 and the Gastroparesis Consortium (GpCRC) supported by the National Institute of Diabetes and Digestive and Kidney Diseases (NIDDK) grants U01DK073983, U01DK073975, U01DK074035, U01DK074007, U01DK073985, U01DK073974, U01DK074008) and the National Center for Advancing Translational Sciences (NCATS) (grants UL1TR000424, UL1TR000093, UL1TR000433, UL1TR000135).

\section{DISCLOSURE}

There were no financial, professional, or personal disclosures from any of the authors.

\section{AUTHOR CONTRIBUTION}

CB, SG, IM, LF, and GF study concept and design, performed the research, analysis and interpretation of data, drafting of manuscript, critical revision of the data for important intellectual content; HP, SH, TA, WS, WH, RM, IS, LAN, KK, JT, FH, PJP study concept and design, performed the research, analysis, interpretation of data, critical revision of the manuscript for important intellectual content; MS, MK, KRS study design, analyzed the data, critical revision of the manuscript for important intellectual content.

\section{REFERENCES}

1 Camilleri M, Parkman HP, Shafi MA, Abell TL, Gerson L. Clinical guide- line: management of gastroparesis. Am I Gastroenterol 2013; 108: 1837; quiz 8.
2 Wang YR, Fisher RS, Parkman HP. Gastroparesis-related hospitalizations in the United States: trends, charac- 
teristics, and outcomes, 1995-2004. Am J Gastroenterol 2008; 103: 31322.

3 Jung HK, Choung RS, Locke GR 3rd, Schleck CD, Zinsmeister AR, Szarka LA, Mullan B, Talley NJ. The incidence, prevalence, and outcomes of patients with gastroparesis in Olmsted County, Minnesota, from 1996 to 2006. Gastroenterology 2009; 136: 1225-33.

4 Bielefeldt K. Gastroparesis: concepts, controversies, and challenges. Scientifica (Cairo) 2012; 2012: 424802.

5 Parkman HP, Hasler WL, Fisher RS. American Gastroenterological Association technical review on the diagnosis and treatment of gastroparesis. Gastroenterology 2004; 127: $1592-$ 622.

6 Hasler WL. Gastroparesis-current concepts and considerations. Medscape I Med 2008; 10: 16.

7 Spangeus A, Suhr O, El-Salhy M. Diabetic state affects the innervation of gut in an animal model of human type 1 diabetes. Histol Histopathol 2000; 15: 739-44.

8 Wang XY, Huizinga JD, Diamond J, Liu LW. Loss of intramuscular and submuscular interstitial cells of Cajal and associated enteric nerves is related to decreased gastric emptying in streptozotocin-induced diabetes. Neurogastroenterol Motil 2009; 21: 1095-e92.

9 Ordog T, Takayama I, Cheung WK, Ward SM, Sanders KM. Remodeling of networks of interstitial cells of Cajal in a murine model of diabetic gastroparesis. Diabetes 2000; 49: 1731-9.

10 Horvath VJ, Vittal H, Lorincz A, Chen H, Almeida-Porada G, Redelman D, Ordog T. Reduced stem cell factor links smooth myopathy and loss of interstitial cells of cajal in murine diabetic gastroparesis. Gastroenterology 2006; 130: 759-70.

11 Choi KM, Gibbons SI, Nguyen TV, Stoltz GJ, Lurken MS, Ordog T, Szurszewski JH, Farrugia G. Heme oxygenase-1 protects interstitial cells of Cajal from oxidative stress and reverses diabetic gastroparesis. Gastroenterology 2008; 135: 2055-64, 64 e1-2.

12 Choi KM, Kashyap PC, Dutta N, Stoltz GJ, Ordog T, Shea Donohue $\mathrm{T}$, Bauer AJ, Linden DR, et al. CD206-positive M2 macrophages that express heme oxygenase-1 protect against diabetic gastroparesis in mice. Gastroenterology 2010; 138: 2399-409, 409 e1.
13 Grover M, Farrugia G, Lurken MS, Bernard CE, Faussone-Pellegrini MS, Smyrk TC, Parkman HP, Abell TL, et al. Cellular changes in diabetic and idiopathic gastroparesis. Gastroenterology 2011; 140: 1575-85 e8.

14 Faussone-Pellegrini MS, Grover $M$, Pasricha PJ, Bernard CE, Lurken MS, Smyrk TC, Parkman HP, Abell TL, et al. Ultrastructural differences between diabetic and idiopathic gastroparesis. I Cell Mol Med 2012; 16: 1573-81.

15 Grover M, Bernard CE, Pasricha PJ, Lurken MS, Faussone-Pellegrini MS, Smyrk TC, Parkman HP, Abell TL, et al. Clinical-histological associations in gastroparesis: results from the Gastroparesis Clinical Research Consortium. Neurogastroenterol Motil 2012; 24: 531-9, e249.

16 Austyn JM, Gordon S. F4/80, a monoclonal antibody directed specifically against the mouse macrophage. Eur $J$ Immunol 1981; 11: 805-15.

17 Mikkelsen HB. Interstitial cells of Cajal, macrophages and mast cells in the gut musculature: morphology, distribution, spatial and possible functional interactions. I Cell Mol Med 2010; 14: 818-32.

18 Mosser DM, Edwards JP. Exploring the full spectrum of macrophage activation. Nat Rev Immunol 2008; 8: 958-69.

19 Gordon S. Alternative activation of macrophages. Nat ReV Immunol 2003; 3: 23-35.

20 Albina JE. On the expression of nitric oxide synthase by human macrophages. Why no NO? I Leukoc Biol 1995; 58: 643-9.

21 Gross TJ, Kremens K, Powers LS, Brink B, Knutson $\mathrm{T}$, Domann FE, Philibert RA, Milhem MM, et al. Epigenetic silencing of the human NOS2 gene: rethinking the role of nitric oxide in human macrophage inflammatory responses. I Immunol 2014; 192: 2326-38.

22 Micklem K, Rigney E, Cordell J, Simmons D, Stross P, Turley H, Seed B, Mason D. A human macrophageassociated antigen (CD68) detected by six different monoclonal antibodies. Br J Haematol 1989; 73: 6-11.

23 Kunisch E, Fuhrmann R, Roth A, Winter R, Lungershausen $\mathrm{W}$, Kinne RW. Macrophage specificity of three anti-CD68 monoclonal antibodies (KP1, EBM11, and PGM1) widely used for immunohistochemistry and flow cytometry. Ann Rheum Dis 2004; 63: 774-84.

24 Adams CW, Poston RN. Macrophage histology in paraffin-embedded multiple sclerosis plaques is demonstrated by the monoclonal panmacrophage marker HAM-56: correlation with chronicity of the lesion. Acta Neuropathol 1990; 80: 208-11.

25 Gown AM, Tsukada T, Ross R. Human atherosclerosis. II. Immunocytochemical analysis of the cellular composition of human atherosclerotic lesions. Am J Pathol 1986; 125: 191-207.

26 Cummings TJ, Hulette CM, Bigner SH, Riggins GJ, McLendon RE. Ham56-immunoreactive macrophages in untreated infiltrating gliomas. Arch Pathol Lab Med 2001; 125: $637-$ 41.

27 Hamann J, Koning N, Pouwels W, Ulfman LH, van Eijk M, Stacey $M$, Lin $\mathrm{HH}$, Gordon $\mathrm{S}$, et al. EMR1, the human homolog of F4/80, is an eosinophil-specific receptor. Eur I Immunol 2007; 37: 2797-802.

28 Kalff JC, Schwarz NT, Walgenbach $\mathrm{KJ}$, Schraut WH, Bauer AJ. Leukocytes of the intestinal muscularis: their phenotype and isolation. I Leukoc Biol 1998; 63: 683-91.

29 Mikkelsen HB, Rumessen JJ. Characterization of macrophage-like cells in the external layers of human small and large intestine. Cell Tissue Res 1992; 270: 273-9.

30 Kalff JC, Turler A, Schwarz NT, Schraut WH, Lee KK, Tweardy DJ, Billiar TR, Simmons RL, et al. Intraabdominal activation of a local inflammatory response within the human muscularis externa during laparotomy. Ann Surg 2003; 237: 301-15.

31 Rugtveit J, Brandtzaeg P, Halstensen TS, Fausa $\mathrm{O}$, Scott $\mathrm{H}$. Increased macrophage subset in inflammatory bowel disease: apparent recruitment from peripheral blood monocytes. Gut 1994; 35: 669-74.

32 Cancello R, Henegar C, Viguerie N, Taleb S, Poitou C, Rouault C, Coupaye M, Pelloux V, et al. Reduction of macrophage infiltration and chemoattractant gene expression changes in white adipose tissue of morbidly obese subjects after surgery-induced weight loss. Diabetes 2005; 54: 2277 86.

$33 \mathrm{He}$ CL, Soffer EE, Ferris CD, Walsh RM, Szurszewski JH, Farrugia G. Loss 
of interstitial cells of cajal and inhibitory innervation in insulin-dependent diabetes. Gastroenterology 2001; 121: 427-34.

34 Vittal H, Farrugia G, Gomez G, Pasricha PJ. Mechanisms of disease: the pathological basis of gastroparesis-a review of experimental and clinical studies. Nat Clin Pract Gastroenterol Hepatol 2007; 4: 336-46.

35 Battaglia E, Bassotti G, Bellone G, Dughera L, Serra AM, Chiusa L, Repici A, Mioli P, et al. Loss of interstitial cells of Cajal network in severe idiopathic gastroparesis. World I Gastroenterol 2006; 12: 6172-7.

36 Forster J, Damjanov I, Lin Z, Sarosiek I, Wetzel P, McCallum RW. Absence of the interstitial cells of Cajal in patients with gastroparesis and correlation with clinical findings. $J$ Gastrointest Surg 2005; 9: 102-8.

37 Harberson J, Thomas RM, Harbison SP, Parkman HP. Gastric neuromuscular pathology in gastroparesis: analysis of full-thickness antral biopsies. Dig Dis Sci 2010; 55: 359-70.

38 Iwasaki H, Kajimura M, Osawa S, Kanaoka S, Furuta T, Ikuma M, Hishida A. A deficiency of gastric interstitial cells of Cajal accompanied by decreased expression of neuronal nitric oxide synthase and substance $\mathrm{P}$ in patients with type 2 diabetes mellitus. I Gastroenterol 2006; 41: 1076-87.

39 Pasricha PJ, Pehlivanov ND, Gomez G, Vittal H, Lurken MS, Farrugia G.
Changes in the gastric enteric nervous system and muscle: a case report on two patients with diabetic gastroparesis. BMC Gastroenterol 2008; 8: 21.

40 Zarate N, Mearin F, Wang XY, Hewlett B, Huizinga JD, Malagelada JR. Severe idiopathic gastroparesis due to neuronal and interstitial cells of Cajal degeneration: pathological findings and management. Gut 2003; 52: 966-70.

41 McKnight AJ, Macfarlane AJ, Dri P, Turley L, Willis AC, Gordon S. Molecular cloning of F4/80, a murine macrophage-restricted cell surface glycoprotein with homology to the G-protein-linked transmembrane 7 hormone receptor family. I Biol Chem 1996; 271: 486-9.

42 Baud V, Chissoe SL, Viegas-Pequignot E, Diriong S, N'Guyen VC, Roe BA, Lipinski M. EMR1, an unusual member in the family of hormone receptors with seven transmembrane segments. Genomics 1995; 26: 334 44.

43 Khazen W, M'Bika JP, Tomkiewicz C, Benelli C, Chany C, Achour A, Forest C. Expression of macrophage-selective markers in human and rodent adipocytes. FEBS Lett 2005; 579: 5631-4.

44 Gough PJ, Gordon S, Greaves DR. The use of human CD68 transcriptional regulatory sequences to direct high-level expression of class A scavenger receptor in macrophages in vitro and in vivo. Immunology 2001; 103: 351-61.

45 Fowler LJ, Maygarden SJ, Novotny DB. Human alveolar macrophage-56 and carcinoembryonic antigen monoclonal antibodies in the differential diagnosis between primary ovarian and metastatic gastrointestinal carcinomas. Hum Pathol 1994; 25: 666-70.

46 Beranek JT. CD68 is not a macrophage-specific antigen. Ann Rheum Dis 2005; 64: 342-3; author reply 3-4.

47 Gottfried E, Kunz-Schughart LA, Weber A, Rehli M, Peuker A, Muller A, Kastenberger M, Brockhoff G, et al. Expression of CD68 in nonmyeloid cell types. Scand I Immunol 2008; 67: 453-63.

48 Villalta SA, Nguyen HX, Deng B, Gotoh T, Tidball JG. Shifts in macrophage phenotypes and macrophage competition for arginine metabolism affect the severity of muscle pathology in muscular dystrophy. Hum Mol Genet 2009; 18: 482-96.

49 Denis M. Human monocytes/macrophages: NO or no NO? I Leukoc Biol 1994; 55: 682-4.

50 Baynes JW. Role of oxidative stress in development of complications in diabetes. Diabetes 1991; 40: 405-12.

\section{SUPPORTING INFORMATION}

Additional supporting information may be found in the online version of this article at the publisher's web site:

Table S1. Primary and Secondary antibodies used. 